\title{
SOBRE A PRESSUPOSIÇÃO DAS CLIVADAS ${ }^{1}$
}

\section{ON THE PRESUPPOSITION OF CLEFTS}

\author{
Sergio Menuzzi \\ Universidade Federal do Rio Grande do Sul \\ Porto Alegre, Rio Grande do Sul, Brasil
}

\begin{abstract}
RESUMO: O presente artigo apresenta um paradoxo relativo às propriedades pressuposicionais das clivadas e propõe uma solução para ele. De um lado, Figueiredo Silva \& Menuzzi $(2014,2015)$ demonstram que clivadas são favorecidas por uma pressuposição de unicidade quando utilizadas como respostas a perguntas $W H$, o que sugere que são caracterizadas por tal pressuposição (cf. WEDGWOOD, 2005, WEDGWOOD et al. 2006, MENUZZI, 2012, BÜRING e KRIZ, 2013). De outro lado, Moretto (2016) e Moretto \& Menuzzi (2016) demonstram que certas clivadas são compatíveis com somente e, portanto, com a asserção de exaustividade; nesse caso, são compatíveis apenas como uma pressuposição mais fraca, de existência (cf. HORN, 1981, 1996). A explicação que proponho para esse paradoxo é a seguinte: uma asserção de identidade fornece uma resposta completa apenas quando há uma pressuposição contextual de unicidade - que não é propriedade inerente das perguntas $W H$ (contra POLLARD \& YASAVUL, a aparecer).
\end{abstract}

PALAVRAS-CHAVE: Clivadas; Pressuposição; Exaustividade; Respostas a perguntas $\mathrm{WH}$.

ABSTRACT: This article presents a paradox regarding the presuppositional properties of the cleft sentences and proposes a solution for it. On the one hand, Figueiredo and Silva \& Menuzzi $(2014,2015)$ demonstrate that clefts are favored by a presupposition of unicity when used as answers to $W H$ questions, which suggests that they are

\footnotetext{
${ }^{1}$ Agradeço a Maria Cristina Figueiredo Silva e a Gian Franco Moretto pelos trabalhos de cooperação com base nos quais pude escrever o presente artigo (e o projeto a partir do qual ele se origina); e agradeço aos dois pareceristas do dossiê comemorativo dos 30 anos do Grupo de Trabalho de Teoria da Gramática da Anpoll pelos vários comentários e sugestões. É claro que todos os erros são de minha total responsabilidade. O presente artigo é financiado por bolsa de produtividade do CNPq (Processo 311254/2016-0).
} 
characterized by such a presupposition (cf. WEDGWOOD, 2005, WEDGWOOD et al. 2006, MENUZZI, 2012, BÜRING and KRIZ, 2013). On the other hand, Moretto (2016) and Moretto \& Menuzzi (2016) show that certain clefts are compatible with only and therefore with the assertion of exhaustivity; in this case, they are compatible only with a weaker presupposition, of existence (cf. HORN, 1981, 1996). The explanation I propose for this paradox is this: an assertion of identity provides a complete answer only when there is a contextual presupposition of unicity - which is not inherent property of $W H$ questions (contra POLLARD \& YASAVUL, to appear).

KEYWORDS: Clefts; Presupposition; Exhaustivity; Answers to $W H$ questions. 


\section{INTRODUÇÃO}

Neste artigo, procuro contribuir para uma melhor compreensão de um dos aspectos informacionais básicos das sentenças clivadas: suas propriedades pressuposicionais. Especificamente, tenho como objetivos: (a) apresentar resultados de trabalhos anteriores que parecem colocar um dilema: clivadas ora parecem apresentar uma pressuposição de unicidade, ora parecem ser incompatíveis com essa pressuposição; e (b) sugerir uma possível solução para esse dilema. $\mathrm{O}$ artigo está organizado da seguinte maneira:

Na seção 2, apresento os resultados de Figueiredo Silva \& Menuzzi (2014, 2015), segundo os quais, quando utilizadas como respostas a perguntas $W H$, clivadas são fortemente favorecidas por uma "pressuposição de unicidade" contextual - i.é, de que somente uma única entidade satisfaz a predicação da clivada. Isso parece indicar que algo como uma "pressuposição de unicidade" é, de fato, um traço convencional das clivadas, cf. a sugestão de vários autores na literatura (WEDGWOOD, 2005, WEDGWOOD et al. 2006, MENUZZI, 2012, BÜRING; KRIZ, 2013).

Mas tal conclusão entra em conflito direto com os resultados de Moretto (2016) e Moretto \& Menuzzi (2016). Como mostrarei na seção 3, uma pressuposição de unicidade é, em geral, incompativel com o uso de somente - o que faz sentido, já que assertar exclusão quando unicidade é pressuposta seria redundante. Entretanto, Moretto (2016) e Moretto \& Menuzzi (2016) demonstram que muitas clivadas são compativeis com somente - logo, são compatíveis com contextos que não pressupõem unicidade: em contextos de asserção de exclusão (e outros), o que aparentemente encontramos é apenas uma pressuposição existencial (cf. HORN, 1981, 1996).

Portanto, a pergunta básica que se deve responder acerca dos aspectos pressuposicionais das clivadas é: o que faz com que as clivadas pareçam pressupor unicidade quando usadas como respostas a perguntas $W H$, mas em outros contextos - por exemplo, quando são compatíveis com somente e, portanto, assertam exclusão - limitem-se no máximo a uma pressuposição existencial?

$\mathrm{Na}$ seção 4 discuto algumas das possibilidades mais específicas de resposta, em particular a de Pollard \& Yasavul (a aparecer), para quem as clivadas adquirem propriedades inferenciais particulares diante de perguntas $W H$ por causa da própria natureza das perguntas $W H$. (Seguem linha similar de análise VELLEMAN et al. 2012 e DESTRUEL, 2017.) Esboçarei uma solução alternativa, em que a "pressuposição de unicidade" não é inerente nem às clivadas, nem às perguntas $W H$; a adequação das clivadas a certas perguntas $W H$ segue de outro fato: clivadas podem ser utilizadas para assertar identidade, e entre os contextos em que tal asserção é relevante encontram-se os de pressuposição de unicidade, como no caso de certos contextos de interrogação WH. 


\section{CLIVADAS COMO RESPOSTAS A PERGUNTAS WH: PRESSUPOSIÇÃO DE UNICIDADE}

Belletti (2009) desenvolveu uma teoria paramétrica da variação tipológica relativa à focalização do sujeito segundo a qual clivadas poderiam ser utilizadas como resposta a perguntas $W H$ "simples" (foco informacional, não contrastivo) em línguas que não dispusessem, de modo "livre", da ordem verbo-sujeito ("V...S", daqui por diante). Italiano seria uma língua em que clivadas não são utilizadas como respostas a perguntas $W H$ de sujeito porque o italiano dispõe da ordem V...S. E a própria Belletti sugeriu que, além do inglês, também o PB seria uma língua que atestaria o caso em que a ausência da ordem V...S livre autoriza o uso de clivadas para responder perguntas $W H$ de sujeito. Segundo Belletti, esta sugestão acerca do PB recebe apoio empírico do trabalho de Guesser (2007); e a diferença entre clivadas de sujeito e objeto em PB veio a ser reforçada por Quarezemin (2009). Evidentemente, se as observações que sustentam essa abordagem estão corretas, precisamos admitir que, pelo menos para clivadas de sujeito, o conteúdo pressuposicional de uma clivada não difere do conteúdo pressuposicional de uma oração com foco no sujeito simplesmente. Isso seria exemplificado pela adequação de ambas as construções em contextos como (1):

A: Quem falou com a Maria?

B: a) O PAULO (falou com ela).

b) Foi O PAULO (que falou com ela).

Exemplos como (1) poderiam sugerir que, no máximo, uma clivada assim como uma oração com foco estreito - possuem uma pressuposição de existência: (1) é compatível com um contexto em que A pressupõe que "alguém falou com Maria". É importante observar que várias abordagens pragmáticas defenderam, precisamente, que o conteúdo pressuposicional de uma clivada é uma proposição existencial - p.ex., Horn $(1981,1996)$ e, mais recentemente, Pollard \& Yasavul (a aparecer), entre vários outros.

De fato, parece frequente o uso de clivadas para responder a perguntas $\mathrm{WH}$ de sujeito em PB. Belletti (2009) reporta o trabalho de Guesser (2007), que montou um experimento de produção controlada exatamente para saber que estratégias de resposta o PB usa. Seus resultados indicam que os falantes nativos de PB respondem a questões $W H$ sobre o sujeito usando clivagem em $50 \%$ das vezes e SV (com foco in situ) em 38\% das vezes. A diferença funcional com relação a clivadas de objeto parece ter sido confirmada por Quarezemin (2009). Quarezemin investigou as estratégias preferidas para responder perguntas $W H$ sobre o objeto, bem como as preferidas para focalizar contrastivamente o objeto, pedindo que os informantes escolhessem a melhor frase, de um conjunto de opções, para estes contextos. Seus resultados impressionam. De 105 sentenças com objeto como foco informacional, 99 exibem ordem SVO; apenas 6 fazem uso de alguma estrutura clivada ( 2 reduzidas e 4 pseudo-clivadas). Por outro lado, em contextos de contraste, a clivagem foi a opção preferida: 59 escolhas em 63 
possibilidades. Esses resultados levam a crer que, no caso de focalização do objeto, SVO é a estratégia preferida para o foco informacional (como previsto por Belletti 2009), e a clivagem é a estratégia principal para veicular foco contrastivo.

Ainda que os dados pareçam robustos, Figueiredo Silva \& Menuzzi (2014, 2015), partindo de outras fontes (WEDGWOOD et al. 2006; MENUZZI, 2012), apontam para o fato de que Belletti (2009), Guesser (2008) e Quarezemin (2009) não controlaram aspectos relevantes observados na literatura semânticopragmática sobre as clivadas. Note-se que, embora (1) acima sugira que foco estreito e clivadas possam ter basicamente a mesma contribuição para o contexto, a adição de material subsequente já coloca em dúvida essa hipótese - o contraste é um dos argumentos de Kiss (1998) para distinguir "foco informacional" de "foco identificacional":

A: Quem falou com a Maria?

B: a) O PAULO falou com ela. A Maria também.

b) Foi O PAULO que falou com ela. ??A Maria também.

A construção de foco informacional simples em (2B.a) pode ser seguida naturalmente da adição de uma alternativa além daquela inicialmente assertada; a clivada em (2B.b), por outro lado, soa estranha quando se tenta adicionar a segunda alternativa. Ou seja: há fatores contextuais relevantes para o uso das clivadas que podem não ter sido evocados - e portanto controlados adequadamente - nos experimentos de Guesser (2008) e Quarezemin (2009), o que pode ter afetado os resultados obtidos. Que fatores são estes?

Vários estudos recentes das clivadas têm procurado explicar os chamados "efeitos de exaustividade" atribuindo a elas uma pressuposição "mais forte" uma "pressuposição de unicidade" ou com conteúdo aproximadamente similar. ${ }^{2}$ Defenderam essa linha de abordagem, p.ex., Wedgwood (2005), Wedgwood et al. (2006), Wedgwood (2009), Menuzzi (2012), Büring e Kriz (2013). Esta abordagem é capaz de explicar o contraste entre (2B.a) e (2B.b). Sem maiores informações, uma pergunta como "Quem falou com a Maria?" pode, de fato, pressupor apenas que alguém (isto é, uma ou mais pessoas) falou com ela, e não

\footnotetext{
${ }^{2}$ Se uma clivada como "Foi João que chegou tarde" pressupõe "unicidade", pressupõe que uma única pessoa $\mathrm{x}$ chegou cedo, e asserta que $\mathrm{x}$ é João. Isso acarreta, evidentemente, que Maria, ou Carlos, etc., não chegaram cedo. Isto é, uma pressuposição de unicidade, em conjunção com a asserção de identidade da clivada, acarreta a exclusão de alternativas, logo possui o mesmo efeito - e por isso poderia explicar - o chamado "efeito de exaustividade" das clivadas. Portanto, para aqueles que defendem que os "efeitos de exaustividade" das clivadas sejam atribuíveis a uma "pressuposição de unicidade", a exaustividade é derivada de uma pressuposição, e não propriamente parte da asserção, das clivadas - contrariamente ao que defende, por exemplo, Kiss (1998), para quem a exaustividade é parte da asserção da clivada.

Observe-se, ainda, que os "efeitos de exaustividade" - sejam eles uma pressuposição ou não - requerem formulações mais complexas com plurais, cf. a nota 3 a seguir. Por isso, Buring \& Kriz (2013), por exemplo, formulam uma "pressuposição de maximalidade", e não de "unicidade" propriamente dita.
} 
que uma única pessoa falou. (3) abaixo ilustra um contexto com essa pressuposição existencial, mais fraca. A meu ver, a clivada não é boa neste contexto:

(3) [A sabe que falaram com Maria, mas não sabe quem ou quantas pessoas; B sabe que várias pessoas falaram com ela:]

A: Quem falou com a Maria?

B: a) O PAULO falou com ela.

b) ?? Foi O PAULO que falou com ela.

Ou seja: (3) sugere que, quando explicitadas as informações adicionais por trás de (2), se não houver uma pressuposição de unicidade, a clivada já não é boa. De fato, a pergunta “Quem falou com Maria?" também é compatível com um contexto em que a pressuposição é de unicidade, como em (4) abaixo; agora, a meu ver, a clivada é natural. Note-se que nesse contexto uma continuação que adicione mais um indivíduo ao conjunto dos que falaram com Maria será inadequada independentemente da estrutura utilizada (por uma razão óbvia: é pressuposto, compartilhado, que foi apenas uma única pessoa):

(4) [A e B viram que uma única pessoa estava falando com Maria:]

A: Quem estava falando com a Maria?

B: a) O PAULO falou com ela. (\#A Maria também.)

b) Era O PAULO que estava falando com ela. (\#A Maria também.)

Em resumo, julgamentos como os reportados em (2)-(4) sugerem que a aparente equivalência entre foco informacional sobre o sujeito e clivadas de sujeito em (1) é simplesmente resultado da indeterminação do contexto em (1): "Quem falou com Maria?" é compatível com um contexto em que há apenas uma pressuposição existencial, em cujo caso foco informacional é OK, mas a clivada não parece ser (cf. (3)); e (1) é compatível também com um contexto em que há uma pressuposição de unicidade, e nesse caso tanto foco informacional quanto a clivada são $\mathrm{OK}$, como em (4). ${ }^{3}$

A fim de verificar se, de fato, as clivadas são condicionadas por uma pressuposição de unicidade, eu e Maria Cristina Figueiredo Silva conduzimos um experimento, que reportamos em Figueiredo Silva e Menuzzi (2015), semelhante ao conduzido por Quarezemin (2009) - com a diferença de que testamos sistematicamente contextos com e sem uma pressuposição de unicidade. Nosso experimento pediu a 12 falantes nativos de PB para ordenar as preferências de

\footnotetext{
${ }^{3} \mathrm{Na}$ verdade, "unicidade" aqui precisa ser melhor formulada para, por exemplo, capturar casos como (I) abaixo; daí as tentativas de incluir, p.ex., "maximalidade" na formulação (ver nota anterior):
}

(I) [A e B viram uma cena em que duas pessoas falavam com Maria:]

A: Quem falou com a Maria?

B: a) O PAULO e a JOANA falaram com ela.

b) Foi O PAULO e a JOANA que falaram ela. 
resposta a questões colocadas em contextos específicos. Cada teste continha quatro histórias-alvo, duas com questões $W H$ sobre o sujeito e duas sobre o objeto; para cada função havia uma questão em um contexto com pressuposição de unicidade, e outra sem essa pressuposição. Os testes apresentavam quatro opções de resposta para os falantes de PB: foco in situ, pseudoclivadas, clivadas completas e clivadas elididas; os exemplos abaixo ilustram os materiais do teste: ${ }^{4}$

(5) [Contexto com pressuposição de unicidade: B está contando para A que foi numa festa em que uma pessoa tirou a roupa e pulou na piscina:]

A: Me conta: quem tirou a roupa?

B: a) Foi o Pedro.

b) O PEDRO tirou a roupa.

c) Quem tirou a roupa foi o Pedro.

d) Foi o Pedro que tirou a roupa.

(6) [Contexto sem pressuposição de unicidade: B está contando ao falante A que foi numa festa super legal:]

A: Quem 'tava lá?

B: a) O PAULO 'tava lá. ${ }^{5}$

${ }^{4}$ Em Figueiredo Silva \& Menuzzi (2015a,b), utilizamos o termo "clivadas elididas" para nos referir às sentenças clivadas que têm elidida sua "oração clivada", isto é, a oração introduzida por que, que é segmentada ("clivada") pelo deslocamento do sintagma $W H$. (5B.a) é um exemplo de "clivada elidida".

Como mencionei, testamos também contextos com foco no objeto direto; (I) abaixo é um exemplo de contextos em que não há pressuposição de unicidade; e (II), a versão em que há tal pressuposição:

(I) [Contexto: B está contando a A que foi a uma festa super legal, etc.]

A: Quem você encontrou lá?

B: Quem eu encontrei lá foi O PAULO. / Foi O PAULO que encontrei lá. / etc.

(II) [Contexto: B está contando a A que foi a uma festa legal, mas que só encontrou uma pessoa conhecida.]

A: Quem você encontrou lá?

B: Eu encontrei O PAULO lá. / Foi O PAULO. / etc.

O experimento também testou materiais similares para o Espanhol Platino, com falantes nativos dessa língua - em particular porque esta língua dispõe da ordem V...S, sendo portanto um caso-teste para a teoria de Belletti (2009). Para maiores detalhes, ver Figueiredo Silva \& Menuzzi (2015b).

${ }^{5}$ Um parecerista comenta que "as opções com ordem SV têm o sujeito em caixa alta", o que indicaria "proeminência prosódica"; mas ele acredita que não há necessidade dessa "proeminência" em (6B.a). Em primeiro lugar, esclareço que estou utilizando caixa alta simplesmente para assinalar o acento de foco (ou "acento nuclear") da frase - e não para assinalar algum "acento mais forte", ou "contrastivo". Na verdade, não é muito fácil saber se há, realmente, diferença entre "acento de foco" de "acento contrastivo" (ver MENUZZI, 2012). Em segundo lugar, me parece que alguma proeminência é necessária em Pedro, em (6B.a), já que este constituinte é o foco informacional da frase. A outra 
b) Quem 'tava lá era o Paulo.

c) Era o Paulo que 'tava lá.

d) Era o Paulo.

Abaixo apresento os principais resultados do experimento, considerando apenas as primeiras opções de resposta (i.é, as opções consideradas pelos informantes como as mais adequadas ao contexto), tanto para questões com foco no sujeito quanto para questões com foco no objeto:

Tabela 1: primeira opção de resposta para questões $W H$ com foco no sujeito e no objeto no PB, segundo o contexto

\begin{tabular}{|c|c|c|c|c|c|c|}
\cline { 2 - 7 } \multicolumn{1}{c|}{} & \multicolumn{3}{c|}{$\begin{array}{c}\text { Contextos com pressuposição } \\
\text { de unicidade }\end{array}$} & \multicolumn{3}{c|}{$\begin{array}{c}\text { Contextos sem pressuposição } \\
\text { de unicidade }\end{array}$} \\
\cline { 2 - 7 } & $\begin{array}{c}\text { Pergunta } \\
\text { Sujeito }\end{array}$ & $\begin{array}{c}\text { Pergunta } \\
\text { Objeto }\end{array}$ & Total & $\begin{array}{c}\text { Pergunta } \\
\text { Sujeito }\end{array}$ & $\begin{array}{c}\text { Pergunta } \\
\text { Objeto }\end{array}$ & Total \\
\hline Foco in situ & 03 & 06 & $\mathbf{0 9}$ & 10 & 10 & $\mathbf{2 0}$ \\
\hline $\begin{array}{c}\text { Clivadas } \\
\text { (plena e } \\
\text { reduzida) }\end{array}$ & 08 & 06 & $\mathbf{1 4}$ & 01 & 01 & $\mathbf{0 2}$ \\
\hline
\end{tabular}

Fonte: (Quadro 6, p. 11, em Figueiredo Silva \& Menuzzi 2015)

O quadro confirma de maneira bastante robusta o papel da pressuposição de unicidade nas escolhas das respostas: sob unicidade, clivadas são preferidas frente ao foco in situ (14 ocorrências contra 9); porém, em contextos sem unicidade, a escolha por clivadas cai dramaticamente, independentemente de estarmos falando de sujeitos ou objetos.

Este estudo, portanto, parece corroborar a posição de muitos autores na literatura sobre as propriedades semântico-pragmáticas das clivadas: as clivadas estão associadas a uma pressuposição de unicidade ou com conteúdo restritivo similar (cf. notas 2 e 3). Os resultados acima e os exemplos discutidos nessa seção também sugerem que a posição de autores como Horn (1981) e Pollard \& Yasavul (a aparecer), por exemplo, não estaria correta: uma pressuposição existencial, apenas, não conseguiria explicar as restrições no uso de clivadas como respostas a perguntas $W H$.

\section{CLIVADAS COM SOMENTE: PRESSUPOSIÇÃO EXISTENCIAL}

Em trabalho recente, reportado em Moretto (2016) e Moretto \& Menuzzi (2016), eu e Gian Franco Moretto temos tentado delimitar melhor qual a

possibilidade de articular a prosódia de (6B.a) seria colocar acento de tópico contrastivo sobre Pedro, e acento de foco sobre o predicado (isto é, sobre lá). Nesse caso (6B.a) teria uma leitura de "tópico implicacional", e veicularia a mensagem de que o falante sabe que o Pedro esteve lá, mas não sabe se outras pessoas estiveram. (Quanto aos acentos de foco e de tópico contrastivo, e as leituras desse último, ver BÜRING, 2003, entre outros.) 
contribuição das clivadas para aquilo que se convencionou chamar de "efeito de exaustividade" estrito senso - a exclusão de alternativas. Para isso, investigamos ocorrências reais de clivadas em textos escritos (também discutidas em TEIXEIRA \& MENUZZI, 2015) ${ }^{6}$; em particular, temos estudado clivadas que são compatíveis com somente - já que somente é tido como a partícula que, por excelência, expressa asserção de exclusão. Note-se, portanto, que no caso das clivadas compatíveis com somente, os efeitos de exaustividade devem ser resultado da asserção da clivada, e não podem ser atribuídos às suas pressuposições. $^{7}$

É importante enfatizar o raciocínio que torna crucial, metodologicamente, a diferença entre clivadas compatíveis e não compatíveis com somente. Nesse raciocínio, é fundamental o pressuposto de que de fato somente seja expressão explícita do ato de assertar a exclusão de alternativas (cf. HORN, 1969, 1996, ROBERTS, 2006, ROOTH, 1986, 1992). No caso das clivadas não compatíveis com somente, trata-se de clivadas que, em princípio, não estão sendo usadas para assertar exclusão de alternativas. Inversamente, as clivadas compativeis com somente são as que estão sendo usadas para assertar exclusão de alternativas. Ora, todas as restrições que encontramos no uso destas últimas, e que não encontramos no uso das primeiras, devem ser restrições resultantes dos conteúdos que são explicitados por somente - isto é, devem ser restrições resultantes do uso da clivada para assertar exclusão, e não restrições inerentes às próprias clivadas (do contrário, estariam presentes também nas clivadas não compatíveis com somente).

Entre outras coisas, os resultados apresentados parcialmente em Moretto (2016) e em Moretto \& Menuzzi (2016) indicam que: (a) diferentemente de somente e ao contrário do que é muitas vezes tido como certo na literatura (por exemplo HORN, 1981, KISS, 1998), a exaustividade das clivadas não pressupõe um conjunto de alternativas contextuais (confirmando TEIXEIRA \& MENUZZI, 2015); isso indica que o efeito primário de focalização do constituinte clivado não é o de excluir alternativas - sendo esse o caso de algumas das clivadas não compatíveis com somente; (b) e, mais importante aqui, as clivadas compatíveis com somente mostram que, contrariamente ao que concluímos na seção precedente e contrariamente a várias propostas recentes (WEDGWOOD, 2005; WEDWOOD et al. 2006; WEDGWOOD, 2009; MENUZZI, 2012; BÜRING \& KRIŽ, 2013), clivadas não pressupõem unicidade ou noções semelhantes; ao

\footnotetext{
${ }^{6} \mathrm{O}$ corpus é constituído de textos coletados em matérias e colunas de revistas e jornais brasileiros, no período entre agosto de 2004 e janeiro de 2005. Especificamente, os trechos em (9) e (11) abaixo foram extraídos das matérias "Yasser Arafat, uma era que se acaba" (Veja, 10/09/2004) e "Cidadania global" (IstoÉ, 12/01/2005), respectivamente. Os trechos são ligeiramente adaptados, com eliminação de material não pertinente ao funcionamento das clivadas.

${ }^{7}$ Cf., também, a discussão na nota 2 acima. Na verdade, como veremos a seguir, quando uma clivada asserta a exclusão de alternativas, ela é incompatível com uma pressuposição de unicidade. Portanto, definitivamente, a exaustividade, nesses casos, não se deve a essa pressuposição.
} 
contrário, parecem ter uma pressuposição mais fraca - uma pressuposição existencial, como argumentado por Horn (1981) e Pollard \& Yasaful (a aparecer), entre outros.

Consideremos, portanto, as propriedades semântico-pragmáticas de somente e o que permitem predizer sobre as clivadas compatíveis com esse modificador. Em geral, a literatura assume que o significado de somente pode ser decomposto em duas implicações, conhecidas como o "prejacente" e a "implicação de exclusão", ilustradas em (7) abaixo. Há discordância quanto ao conteúdo preciso e ao status dessas implicações. Em nosso estudo, seguimos a linha proposta pela primeira vez por Horn (1969; ver também HORN, 1996; ROBERTS, 2006): um enunciado com somente pressupõe o prejacente (cf. (7a)) e asserta a exclusão de suas alternativas contextuais (cf. (7b)): ${ }^{8}$

(7) Somente Maria gosta de João.

a) Prejacente (pressuposição):

"Maria gosta de João."

b) Implicação da Exclusão (asserção):

"Ninguém além de Maria gosta de João."

Assumindo a análise acima, Moretto (2016) e Moretto \& Menuzzi (2016) preveem que somente só seria aceitável com uma clivada nas seguintes condições (a condição (8c) abaixo deriva da suposição de que a asserção de exclusão requer alternativas dadas no contexto, cf. ROOTH, 1986, 1992):

(8) a) O prejacente pode ser considerado como sendo de algum modo pressuposto no contexto (é dado ou inferível).

b) Assertar a exclusão é relevante; em particular, unicidade não é pressuposta (já que unicidade implica a exclusão de alternativas). ${ }^{9}$

c) Existem alternativas explícitas a ser excluídas no contexto.

De fato, em nossos estudos, descobrimos que clivadas compatíveis com somente satisfazem todas as condições em (8), o que pode ser ilustrado por (9) abaixo:

(9) Yasser Arafat fez seu gesto mais difícil quando aceitou a existência de Israel: as negociações de paz estavam num impasse; a violência prevalecia; os EUA de George W. Bush - a única força capaz de obter uma solução - não fazia nada; o próprio Arafat acumulava repetidamente fracassos e traições. Foi (somente) o seu gesto de grandeza que lhe rendeu um lugar numa história com tantos personagens mais importantes que ele.

\footnotetext{
${ }^{8}$ A primeira suposição foi qualificada em Horn (1996) e Roberts (2006), que na verdade argumentam que se trata se um tipo de "background inference" ligeiramente diferente das pressuposições tradicionais. A distinção não afeta significativamente a argumentação apresentada aqui.

9 Isto é, se unicidade é pressuposta, a asserção de exclusão será redundante - portanto pragmaticamente imprópria. Ver exemplo (10) abaixo.
} 
O prejacente ("O gesto de grandeza de Arafat lhe rendeu um lugar na história") é inferível no contexto (de "Arafat fez seu gesto mais difícil..." e do conhecimento compartilhado de que Arafat foi personagem importante nos conflitos do Oriente Médio). Não há pressuposição de unicidade no contexto: nada anterior à clivada leva o leitor a esperar que somente uma única coisa "rendeu a Arafat um lugar na história" - portanto, assertar a exclusão de alternativas no contexto seria relevante. E existem alternativas contextuais ao gesto de Arafat a serem excluídas - pois poderiam ter-lhe rendido um lugar na história, mas, segundo o texto, não o fizeram: seus fracassos e suas traições. Todas as condições para o uso de somente - a partícula que asserta exclusão - são satisfeitas; e de fato somente é aceitável no contexto. (MORETTO, 2016, apresenta resultados de um experimento de julgamento confirmando esta e as demais observações dessa seção.)

Enfatize-se o aspecto fundamental de (9) - e dos outros casos que discutimos em nosso trabalho: clivadas podem ser usadas para assertar exclusão, em cujo caso não pressupõem unicidade. Em vez disso, a clivada em (9) - e todas as demais envolvendo asserções de exclusão com somente - apresentam o prejacente como pressuposição. Evidentemente, o prejacente acarreta uma outra pressuposição, mais fraca: uma pressuposição existencial. No caso de (9), é inferível do contexto (e é conhecimento compartilhado) que "algo rendeu a Arafat um lugar na história". Ou seja, os casos em que as clivadas podem ser usadas para a asserção de exclusão - e podem, portanto, ser acompanhadas de somente - não são compatíveis com a tese de que carregam, inerentemente, uma pressuposição de unicidade; mas são compatíveis com a tese de Horn (1981), segundo a qual carregam uma pressuposição existencial, apenas.

Note-se aqui que o uso de clivadas com somente revela que as clivadas não exigem uma pressuposição de unicidade - ou seriam incompatíveis com somente; mas isso não significa que sejam incompativeis com essa pressuposição. De fato, seria surpreendente se fossem, dado o que vimos na seção anterior. Pode-se inclusive confirmar a tese de que a ausência de pressuposição de unicidade cria um problema para a asserção de exclusão - e para somente - mas não para a clivada. Considere-se o seguinte exemplo (construído; julgamentos confirmados experimentalmente, cf. MORETTO, 2016):

(10) O projeto submetido pelo Senador Almeida Júnior foi aprovado pelos demais senadores no prazo recorde de uma semana. E, um mês depois, teve sua redação criticada por praticamente todo o Congresso, inclusive pelo Senador Almeida Júnior, o que é curioso, já que foi (??somente) ele que submeteu o projeto.

A clivada sem somente é perfeitamente aceitável em (10). E só há uma razão pela qual somente parece inadequado: a presença de uma pressuposição de unicidade (a primeira frase deixa claro para o interlocutor que o Senador Almeida Júnior foi o único a submeter o projeto). As demais condições para o uso de somente são satisfeitas: o prejacente é pressuposto contextualmente e há alternativas relevantes - os demais senadores. 
A fim de encerrar esta discussão dos resultados de nosso estudo sobre clivadas com somente, quero apresentar apenas mais um dos resultados, que será pertinente para a discussão posterior aqui. Neste caso, o resultado relevante é fornecido por uma clivada que, em princípio, é incompatível com somente:

(11) Em 2005, o mundo inteiro se uniu para ajudar os sobreviventes do tsunami que deixou 150.000 vítimas na Ásia e África. Isso levou a filial da Unicef ("Fundo das Nações Unidas para a Infância") no Brasil a quebrar uma regra antiga. De acordo com José Afonso Braga, diretor do setor de arrecadação de fundos, "estávamos habituados a aplicar nossos recursos só aqui no país. Mas dado o forte desejo dos brasileiros em ajudar os atingidos pelo tsunami, decidimos abrir uma operação de captação de recursos para esse fim específico. Foi (??somente) a enorme pressão popular que nos levou a esta mudança."

O prejacente ("a pressão popular levou a Unicef brasileira a mudar seu modo de operação") é pressuposto (é dado pela frase anterior). Além disso, não há nenhum pressuposto de unicidade no contexto: nada leva a esperar que apenas uma única coisa "levou a Unicef a mudar"; portanto, a asserção de exclusão seria relevante no contexto. No entanto, não há alternativas contextuais explícitas ou sequer sugeridas para "a enorme pressão popular" - e esta é a razão pela qual somente parece inadequada. Note-se, entretanto, que a clivada sem somente é perfeitamente aceitável. Para confirmar que o problema com somente é a ausência de alternativas contextuais, observe a versão abaixo do mesmo texto, ligeiramente modificada de modo a oferecer alternativas relevantes (em Itálico) para o constituinte clivado:

(12) [...] De acordo com José Afonso Braga, diretor do setor de arrecadação de fundos, "estávamos habituados a aplicar os nossos recursos só aqui no país. Mas dado o forte desejo dos brasileiros em ajudar os atingidos pelo tsunami, decidimos abrir uma operação de captação de recursos para esse fim específico. Em outras tragédias internacionais, a imprensa já havia sugerido que mudássemos nossos procedimentos. Mas foi (somente) a enorme pressão popular que nos levou agora ajudar as vítimas do tsunami."

O exemplo (12) confirma que alternativas contextuais são necessárias para a asserção de exclusão e para o uso de somente. Por outro lado, (11) revela que, ao contrário, seja lá qual for o efeito que as clivadas obtêm ao focalizar o constituinte clivado, este efeito não pode ser equacionado com o de "asserção de (uma alternativa por) exclusão (de outras alternativas dadas contextualmente)". Definitivamente, a função "inerente" da focalização do constituinte clivado não é expressar necessariamente "exaustividade".

Em resumo, quanto à unicidade: a discussão acima mostra que, contrariamente ao que muitos trabalhos recentes propõem e ao que apresentamos na seção anterior deste artigo, clivadas não pressupõem, necessariamente, unicidade ou noções semelhantes (contra WEDGWOOD, 2009; MENUZZI, 2012; BÜRING \& KRIŽ, 2013, etc.). Ao contrário, os casos acima discutidos e outros apresentados em Moretto \& Menuzzi (2016) indicam que as clivadas 
apresentam, no máximo, uma pressuposto existencial, como proposto por Horn (1981) e defendido, mais recentemente, por Pollard \& Yasavul (a aparecer).

\section{QUAL, AFINAL, É A PRESSUPOSIÇÃO DAS CLIVADAS?}

Creio que a discussão nas seções precedentes deixa claro o paradoxo colocado pelo comportamento pragmático das clivadas. (a) De um lado, quando observamos o uso de clivadas como respostas a perguntas $W H$, verificamos que há forte evidência de que, neste contexto, são respostas felizes quando o contexto da pergunta apresenta uma pressuposição de unicidade (ou noção similar, cf. notas 2 e 3). (b) Por outro lado, há evidência clara, também, de que em vários outros contextos discursivos, o efeito de focalizar o constituinte clivado requer, para seu sucesso contextual, no máximo uma pressuposição de existência. Esse é, em particular, o caso em que a clivada é utilizada para se fazer uma asserção de exclusão (caso em que é compatível com somente); mas também é o caso de outros efeitos de focalização que não envolvem necessariamente exclusão de alternativas (p.ex., também é o caso do exemplo (1), discutido na introdução).

O paradoxo que se coloca, então, é: qual a propriedade pressuposicional básica das clivadas? é uma pressuposição de unicidade, como defendido por Wedgwood (2009), Menuzzi (2012), Büring \& Križ (2013), entre outros? ou é uma pressuposição existencial, como defendido por Horn (1981) e Pollard \& Yasavul (a aparecer)? No que segue, pretendo esboçar uma linha de raciocínio que pode responder a este desafio.

Por várias razões, parto da hipótese de que a propriedade pressuposicional básica das clivadas corresponde ao fechamento existencial da oração clivada, ${ }^{10} \mathrm{e}$ sua contribuição para o contexto é assertar a identidade de uma entidade que satisfaça a pressuposição com a denotação do constituinte clivado. Trocando em miúdos, minha hipótese é a de que a semântica de uma clivada informacionalmente segmentada como em (13) corresponda a algo como (14): ${ }^{11}$

$$
\begin{aligned}
& \text { [Foco Foi João] [Pressuposição que encontrou Maria]. } \\
& \lambda \mathrm{s}: \exists \mathrm{x}[\text { Encontrou (x, Maria })] \text { in s . x = João em s }
\end{aligned}
$$

${ }^{10}$ A hipótese vale para os casos de clivadas em que o material pressuposicional é expresso pela oração clivada, como em (13); é preciso, entretanto, lembrar que há casos em que, aparentemente, ao menos a clivada é "informação nova" - casos que Prince (1978) chama de "pressuposição informativa". (Ver HEDBERG, 2013 para discussão recente.) Estes são casos que precisarei estudar melhor no futuro.

11 Como observa um parecerista, (14) é apenas uma formulação um pouco mais formalizada de uma análise com uma história relativamente longa, remontando aos insights originais de Chomsky e Jackendoff, que é encontrada em vários autores, por exemplo em Horn (1981) e Zubizarreta (1998). 
Segundo (14), (13) terá um valor de verdade numa situação que satisfaça a pressuposição de que existe pelo menos um x que encontrou Maria; satisfeita esta condição, será verdadeira se $\mathrm{x}$ for idêntico a João na referida situação, e falsa de outro modo; e (13) será indefinida - portanto, uma asserção inapropriada - se a situação s não satisfizer a condição de que exista pelo menos um x que encontrou Maria em s.

Apenas mencionarei brevemente as razões iniciais pelas quais creio que essa abordagem me parece correta - é claro que algumas dessas razões terão de ser desenvolvidas posteriormente.

A primeira reside no fato de que os contextos em que há pressuposição existencial são mais gerais, enquanto que a pressuposição de existência parece ser exigida em contextos específicos - por exemplo, no caso de perguntas $W H$. Em segundo lugar, uma pressuposição de existência sempre será satisfeita por um contexto com pressuposição de unicidade, mas o contrário não acontece: portanto, parece mais fácil derivar a pressuposição de unicidade de alguma restrição adicional derivada do contexto. Em terceiro lugar, a análise em (14) é extremamente próxima à sintaxe de superfície da clivada, sendo quase que sua análise mínima. A asserção de identidade é obviamente o que é codificado sintaticamente pela cópula e o constituinte clivado. E a pressuposição corresponde à oração clivada, o que é quase ótimo: a oração clivada tem a forma de uma relativa, e relativas são basicamente funções proposicionais (isto é, expressões com uma variável aberta que podem ser convertidas em predicados por meio de um operador lambda; ver, por exemplo, HEIM \& KRATZER, 1998). Portanto, se o conteúdo proposicional de uma oração clivada introduzida por que puder ser computado composicionalmente como se computa o conteúdo proposicional de uma relativa introduzida por que, tudo o que é necessário é derivar o fechamento existencial da clivada; e, para isso, há vários instrumentos disponíveis (por exemplo, na teoria de Givenness de SCHWARZCHILD, 1999, material desacentuado deve ser "dado" e fechado sob "existential closure"). Me parece relativamente claro que não será complicado encontrar uma análise da sintaxe de (13) que resultará composicionalmente na semântica em (14). Como disse, são várias as razões iniciais para adotar uma linha de análise como a esboçada em (14).

Agora, sob esta perspectiva as perguntas que se colocam são as seguintes: por que a pressuposição existencial em (14) parece ser "reforçada" para uma pressuposição de unicidade nos casos de respostas a perguntas $W H$ (cf. (4) acima)? por que "foco informacional in situ" simplesmente não exige esta pressuposição, e pode servir de resposta a uma pergunta $W H$ cuja pressuposição seja meramente existencial (cf. (3))?

A linha de análise que esboço aqui me foi sugerida pela proposta de Pollard \& Yasaful (a aparecer; P\&Y daqui por diante). Estes autores argumentam que, no caso geral, não há necessidade de se afirmar que as clivadas são "exaustivas": seus usos não teriam como finalidade "excluir alternativas", mas sim "especificar (ainda mais) um referente do discurso que o falante considera insuficientemente especificado". Incluem nesta idéia de que a clivada não "exclui alternativas", mas "especifica um referente", casos que, na verdade, a literatura 
consideraria como exemplos típicos de uma "identificação por exclusão": casos em que a clivada é usada para "foco contrastivo", i.é, para rejeitar ou corrigir uma identificação anterior, como em (15) abaixo ((6), p. 2, em P\&Y). Mas também incluem casos em que, realmente, faz mais sentido dizer que o papel da clivada é "especificar mais" um referente do discurso do que "identificar por exclusão", como (16) ((7), p. 2, em P\&Y):

A: Did you see? The black cat caught a bird!

$\mathrm{B}$ : I think it was the grey one.

A: A gas station was robbed by a man wearing a sombrero!

B: Yeah,...

a) it was the BP station near the Bethel intersection (that was robbed).

b) it was my halfwit brother (who robbed it).

Nas próprias palavras de $\mathrm{P} \& \mathrm{Y}$, "there is no need to say they [as clivadas] implicate that the entities denoted by the focused expressions are the maximal entities with respect to some property under discussion" (p. 2), isto é, que são as únicas entidades a satisfazer a propriedade expressa pela oração clivada. Portanto, para $\mathrm{P} \& \mathrm{Y}$ as clivadas não são, em geral, exaustivas - e por isso uma pressuposição de unicidade (ou "maximalidade") seria forte demais. ${ }^{12}$ Mas reconhecem que, em perguntas $W H$, elas são (ou, eu diria, podem ser...) "exaustivas" - contrariamente ao foco puramente informacional. O exemplo que oferecem ((3), p. 1) é análogo ao exemplo (2) acima:

(17) Who went to CLS? ? $^{13}$

a) Greg and Dan. I don't know if anyone else did. / Scott did, too.

${ }^{12}$ A conclusão de $P \& Y$ está correta - de fato, as clivadas não podem ser tomadas como inerentemente exaustivas porque é sabido que, em vários contextos, a exaustividade é suspensa (ver, por exemplo, RODRIGUES \& MENUZZI, 2010; TEIXEIRA \& MENUZZI, 2015 e referências lá citadas). Mas a argumentação empírica de P\&Y é bastante frágil: na verdade, em todos os casos que sustentam não ser necessário dizer que há implicação de exaustividade, na verdade há tal implicação: são todos casos em que há pressuposição de unicidade no contexto, e esta pressuposição parece ser parte daquilo que autoriza o uso da clivada em tais contextos! Considere-se, por exemplo, o contexto em (15): se fosse alterado de modo a não pressupor unicidade, a clivada se tornaria insuficiente, cf. (I); note-se ainda que não é "correção da identidade do referente" em si - isto é, "contraste" - que é crucial em (15), mas unicidade, cf. (II):

(I) A: Did you see? Those animals caught the bird!

B: a) ?? I think it was the black cat.

b) I think it was the black cat only.

(II) A: Did you see? An animal caught the bird!

B: I think it was the black cat.

${ }^{13}$ A pedido de um dos revisores, esclareço que "CLS" aqui se refere a um dos encontros da Sociedade Linguística de Chicago ("Chicago Linguistic Society"). 
b) It was Greg and Dan. \#I don't know if anyone else did. / \#Scott did, too.

Ou seja: por caminho diferente (e provavelmente incorreto: ver nota 12), P\&Y chegaram basicamente ao mesmo problema que levantei neste artigo - ainda que o formulem de modo diferente: para eles, trata-se de dizer que, diferentemente de outros contextos típicos de uso das clivadas, nas perguntas $W H$ as clivadas "implicam" (ou, na hipótese que esboçarei abaixo, acarretam) exaustividade; na minha formulação, trata-se de dizer que, diferentemente de outros contextos típicos de uso, nas perguntas $W H$ as clivadas são felizes apenas se houver uma pressuposição contextual de unicidade.

Qual a solução que P\&Y propõem? Para eles, a restrição é basicamente resultado da interação da semântica das perguntas $W H$ com a semântica das clivadas. Especificamente, $\mathrm{P} \& \mathrm{Y}$ adotam, para as perguntas $W H$, uma semântica baseada em Hamblin (1957, 1971), segundo a qual: (I) uma pergunta denota um conjunto de proposições - o conjunto de suas possíveis respostas completas; (II) as respostas completas devem, em seu conjunto, ser exaustivas e mutuamente exclusivas. Dentro deste framework, P\&Y propõem que, para cada pergunta $W H$, cada possível resposta completa corresponde a uma escolha particular de uma pluralidade máxima (possivelmente vazia ou correspondente a um único átomo) que possui a propriedade expressa pela pergunta. Assim esboçada a teoria (ver P\&Y para implementação técnica), os autores propõem a seguinte análise para o contraste em (17):

"Upon acceptance [da pergunta], specifying this maximal plurality becomes a commitment of the interlocutors [i.é, parte do common ground]. Given this effect of the question on the context, the contrast between [(17a)] and [(17b)] arises because in $[(17 b)]$ the it-cleft identifies [porque asserta identidade] the maximal plurality of individuals with the property of going to CLS with the entity denoted by the focused expression. But no such identification necessarily exists in [(17a)], because we analyze non-cleft short answers as, in general, providing only partial information about the identity of the maximal plurality in question. Put differently, [(17a)] says that Greg and Dan are two atoms of the maximal plurality of individuals with the property of going to CLS whereas [(17b)] says that that maximal plurality is the plurality with the two atoms Greg and Dan" (P\&Y, p. 4).

Como se vê, a idéia é que perguntas $W H$ carreguem elas próprias o requisito semântico de que se busca a "entidade máxima" (portanto, única) que satisfaz a propriedade expressa pela pergunta. E, aceitando uma pergunta, este requisito é incorporado ao common ground, sendo, portanto, presumido por quem responde. Isto é, para P\&Y uma pergunta, quando é aceita pelo interlocutor, necessariamente aciona uma pressuposição de maximalidade/unicidade. Neste contexto, assertar identidade - como faz a clivada - significa identificar a entidade máxima/única que a aceitação da pergunta determina como o objetivo do discurso. 
A meu ver, a proposta de $\mathrm{P} \& \mathrm{Y}$ tem de enfrentar imediatamente dois problemas graves. Claramente, não pode ser uma propriedade semântica, inerente, das perguntas $W H$ que elas exijam, como resposta, a "entidade máxima" que satisfaça a propriedade que expressam: afinal de contas, vimos que perguntas WH ora pressupõem, ora não pressupõem, esta "maximalidade/unicidade" (ver discussão na seção 2). Além disso, parece bastante ad hoc que - uma vez aceita a pergunta (e aceito o compromisso de buscar a entidade máxima que satisfaz a propriedade expressa pela clivada) - exatamente a estrutura informacional não marcada, foco informacional simples, não implique esta "entidade máxima". De fato, P\&Y são obrigados a adotar uma pragmática inusual para foco informacional, que evita a implicação de exaustividade, quando na verdade foco informacional normalmente implica exaustividade (pela Máxima da Quantidade; ver WEDGWOOD, 2005; MENUZZI, 2012 para discussão). ${ }^{14}$

Estes aspectos específicos da abordagem de P\&Y são pouco promissores; mas me parece muito boa a idéia de que as restrições das clivadas enquanto respostas a perguntas $W H$ resultem da interação das propriedades semânticopragmáticas das perguntas com as propriedades semântico-pragmáticas das clivadas - em particular, do fato de que clivadas são asserções de identidade - o que corresponde transparentemente à sua sintaxe.

Lembremos que as clivadas parecem exigir, para responder a perguntas $W H$, que estas pressuponham unicidade. Isso sugere uma resposta bem mais simples para a oposição entre clivadas e sentenças com foco informacional simples. Quanto a estas: em um contexto que pressupõe unicidade, assertar uma das alternativas contextuais implica que a resposta é "completa", portanto, exaustiva; mas implicaturas podem ser canceladas facilmente (ver WEDGWOOD, 2005; MENUZZI, 2012). Isso explica o comportamento das estruturas de foco informacional simples em exemplos como (2) e (17).

Quanto às clivadas: em um contexto que pressupõe unicidade, a asserção de identidade não implica, apenas, exaustividade - a exaustividade é obviamente um acarretamento do pressuposto contextual com a asserção da clivada! ${ }^{15}$ Isso

\footnotetext{
${ }^{14} \mathrm{Na}$ formulação clássica de Grice (1975), a Máxima da Quantidade exige que o falante faça uma contribuição conversacional tão informativa quanto necessária, isto é, nem mais nem menos informativa do que requerido naquele ponto da interação verbal. Mais abaixo, menciono ainda a exigência de relevância, que Grice também codificou como uma Máxima: o falante deve fazer uma contribuição que seja pertinente - isto é, que tenha relação - com os objetivos da interação verbal. No framework que estou assumindo aqui, esta última máxima é reconcebida, na verdade, como a exigência de congruência entre a "pergunta em discussão" e a contribuição do falante (ver ROBERTS, 1996 e referências lá citadas).

15 A pressuposição contextual é a de que "um único x é tal que $\mathrm{P}(\mathrm{x})$ "; a clivada pressupõe que "existe um $\mathrm{x}$ tal que $\mathrm{P}(\mathrm{x})$ " (satisfeita pela pressuposição contextual) e asserta que "para todo $\mathrm{x}$ tal que a pressuposição da clivada é satisfeita, $\mathrm{x}=a$ " em que $a$ é a entidade denotada pelo constituinte clivado. Segue-se logicamente dessas proposições que "um único $\mathrm{x}$ é tal que $\mathrm{P}(\mathrm{x})$ e $\mathrm{x}=a$ ". Na verdade, basicamente este é o mesmo resultado que o obtido por $\mathrm{P} \& \mathrm{Y}$, salvo que para estes autores ele segue da semântica, e
} 
explicaria porque clivadas "comprometem" mais o falante com a exaustividade do que a simples asserção de uma alternativa, i.é, porque comprometem mais que uma frase canônica com foco informacional, explicando os contrastes em (2) e (17).

Mas esse raciocínio ainda não explicaria por que clivadas são estranhas quando não há pressuposição de unicidade no contexto da pergunta $W H$. Aqui, me parece, será preciso invocar uma outra noção pragmática - e não semântica, como na abordagem de P\&Y - para explicar a restrição: relevância. A meu ver e aqui a análise passa a ser um esboço, apenas - pode-se obter o resultado desejado explorando um framework particular para a noção de relevância: o framework das "perguntas sob discussão" [QUDs] proposto por Roberts (1996).

Considere-se, desta perspectiva, a restrição no uso de clivadas - isto é, da asserção de identidade - no contexto de uma pergunta $W H$ em que não há pressuposição de unicidade/maximalidade. Neste contexto, obviamente a asserção de uma ou mais das alternativas potenciais satisfaz a "pergunta em discussão", já que justamente não há expectativa de uma resposta "completa". Mas qual seria a relevância de assertar identidade - isto é, de usar uma clivada? Talvez, implicar unicidade/exaustividade? Mas implicaturas precisam de motivação pragmática adicional - ou, pela máxima da quantidade, o interlocutor esperará simplesmente a asserção direta correspondente. Considere-se o seguinte caso:

(18) [A e B viram que muitas pessoas pareciam estar falando com Maria, mas não conseguiram reconhecê-las; mais tarde, B soube que apenas uma delas, o Paulo, de fato falou com Maria; A, evidentemente, ainda pressupõe que mais de uma pessoa estava falando com Maria:]

A: Quem tava falando com a Maria ontem?

B: a) ?? Na verdade, O PAULO 'tava falando com ela.

b) ?? Na verdade, era O PAULO que 'tava falando com ela.

c) Na verdade, só O PAULO 'tava falando com ela. ${ }^{16}$

Como se vê, de fato, em contextos em que não há pressuposição de unicidade, usar uma clivada é estranho (ao menos, se não houver nada que justifique, adicionalmente, a implicação de exclusão); mas não é estranho usar somente - precisamente porque somente asserta a exclusão.

não da pragmática, das perguntas $W H$ - razão pela qual a proposta acaba não explicando adequadamente o contraste com foco informacional simples.

${ }^{16}$ Os julgamentos reportados aqui são os meus, checados informalmente com duas ou três pessoas. Um dos pareceristas, entretanto, objeta que, para ele, além de (18B.c), também (18B.b) é boa - presumo que totalmente aceitável - no contexto. Lamentavelmente, este caso não está incluído entre os testados experimentalmente por Moretto (2016); portanto, ainda não há evidência experimental para escorar os julgamentos que reporto aqui. 


\section{CONCLUSÃO}

Em resumo, a explicação que estou sugerindo para a restrição no uso de clivadas com perguntas $W H$ é a de que, para uma clivada ser utilizada com felicidade em um contexto, é preciso que assertar identidade seja "relevante" ao contexto - isto é, contribua da maneira esperada para a "pergunta sob discussão". É o que acontece quando há uma pressuposição da unicidade - quando clivada e contexto juntos acarretam exaustividade.

Note-se que este modo de colocar a questão altera completamente o modo de explicar os vários usos das clivadas. Agora, será preciso explicar por que assertar identidade é relevante, por exemplo, nos casos em que a clivada é utilizada para assertar exclusão - isto é, nos casos em que é compatível com somente. E será preciso explicar por que assertar identidade é relevante nos contextos em que as clivadas não têm como efeito a exaustividade - por exemplo, no contexto (1) da introdução. É bem provável que, em muitos casos, o efeito seja "especificar um referente que não está suficientemente especificado" - como sugeriram P\&Y. Esse novo olhar sobre as clivadas terá de ser explorado para saber se a análise que sugeri aqui está no caminho correto.

Além disso, há um outro conjunto de questões que se colocam a partir do modo como justifiquei a análise da semântica básica das clivadas - com base na correspondência mais óbvia com a superfície da sintaxe dessas frases. Se essa justificativa está correta, basicamente a mesma semântica terá de ser atribuída às demais construções clivadas - por exemplo, às pseudoclivadas e às pseudoclivadas invertidas -, já que os recursos morfossintáticos de superfície que utilizam são basicamente os mesmos (pronomes $W H$ e a cópula). E as diferenças "funcionais" entre clivadas, pseudoclivadas, etc. - se as houver, e as há, como o artigo clássico de Ellen Prince (PRINCE, 1978) o demonstra - terão de ser tratadas puramente pelo componente informacional da frase e o modo como é mapeado na estrutura de pressuposição/asserção do enunciado. Mas essa abordagem não chega a ser uma novidade, já tendo sido explorada por outros autores (por exemplo, HEDBERG, 1990, 2013).

\section{REFERÊNCIAS}

BELLETTI, A. Answering Strategies. In: BELLETTI, A. Structures and Strategies. 1. ed. Routledge: New York/London, 2009. cap. 10, p. 242-265.

BÜRING, D.; KRIZ, M. It's That, and That's It! Exhaustivity and Homogeneity Presuppositions in Clefts (and Definites). Semantics \& Pragmatics. n. 6, [s.1.], 2013, p. 1-29.

DESTRUEL, E. The pragmatics of French (non-)prototypical clefts: influence of the type of question on naturalness and interpretation. Journal of Pragmatics, 
v. 121, p. 58-75, [s.1.], nov. 2017. Disponível em: $<$ https://www.sciencedirect.com/science/article/pii/S0378216617302801>.

Acesso em: 2017

FIGUEIREDO SILVA, M. C.; MENUZZI, S. M. Sobre o uso de sentenças clivadas como resposta a perguntas WH. In: VII Workshop do Grupo Romania Nova. 2014, Buenos Aires: Universidad de Buenos Aires.

FIGUEIREDO SILVA, M. C.; MENUZZI, S. M. Mais sobre o uso de sentenças clivadas como resposta para perguntas WH. In: Anais do IX Congresso Internacional da Abralin. Belém do Pará: UFPA, 2015. p. 1-13

GRICE, H. P. Logic and conversation. In: COLE, P. et al. Speech Acts, Syntax and Semantics. Nova Iorque: Academic Press, vol. 3. 1975. p. 41-58.

GUESSER, S. Soggetto nullo e focalizazzione del soggetto in portoghese brasiliano. Siena, Toscana: 2007. 137f. Dissertação (Mestrado em Linguística) Facoltà di Lettere e Filosofia, Università di Siena, Siena.

HEDBERG, N. Discourse pragmatics and cleft sentences in English. Minneapolis, Minnesota: 1990. 198f. Tese de doutorado em Linguística. University of Minnesota.

HEDBERG, N. Multiple focus and cleft sentences. In: HARTMANN, K; VEENSTRA, T. (eds). Cleft Structures. John Benjamins: Amsterdam, 2013. p. 227-250.

HORN, L. A pressupositional analysis of only and even. In: Proceedings of the $5^{\text {th }}$ Annual Meeting of the CLS. Chicago: University of Chicago, 1969, p. 97-108.

HORN, L. Exhaustiveness and the Semantics of Clefts. Proceedings of NELS, n. 11, [s.1.], 1981, p. 125-142.

HORN, L. Exclusive company: only and the dynamics of vertical inference. Journal of Semantics, n. 13, [s.1.], 1996, p. 10-40. Disponível em:

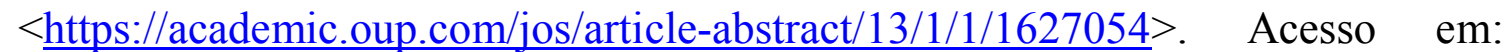
2017

KISS, K. É. Identificational Focus and Information Focus. Language, n. 74, [s.1.], 1998, p. 245-273. Disponível em: <https://www.jstor.org/stable/417867>. Acesso em: 2017

MENUZZI, S. Algumas observações sobre foco, contraste e exaustividade. Revista Letras. UFPR, Curitiba, n. 86, 2012, p. 95-121, 2012.

MORETTO, G. F. Efeitos de exaustividade em clivadas e a semântica de 'somente'. Porto Alegre, RS: 2016. 273f. Dissertação de mestrado em Estudos da 
Linguagem, Programa de Pós-Graduação em Letras, Universidade Federal do Rio Grande do Sul.

MORETTO, G. F.; MENUZZI, S. M. Only and clefts: an empirical study. Trabalho apresentado no XI Workshop on Formal Linguistics. UFPR, Curitiba, nov. 2016.

POLLARD, C.; YASAVUL, M. Anaphoric clefts: the mith of exhaustivity. Proceedings of CLS 2014. Chicago, Illinois: Chicago Linguistic Society, 2014. (no prelo)

QUAREZEMIN, S. Estratégias de focalização no português brasileiro: uma abordagem cartográfica. Florianópolis, SC: 2009. 198f. Tese de doutoramento em Linguística. Universidade Federal de Santa Catarina.

ROBERTS, C. Information Structure: towards an integrated theory of formal pragmatics. In: Yoon \& Kathol (eds.). OSU Working Papers in Linguistics. Columbus, Ohio, n. 48, 1996, p. 91-136.

ROBERTS, C. Only, pressuposition and implicature. Journal of Semantics. [s.1.], 2006. Ms., Ohio State University. Disponível em: $<\underline{\text { https://www.asc.ohio- }}$ state.edu/roberts.21/only.pdf>. Acesso em: 2017

ROOTH, M. Association with Focus. Amherst, Massachusetts: 1985. 237 f. Tese de doutorado em Linguística. University of Massachusetts.

ROOTH, M. A theory of focus interpretation. Natural Language Semantics, n. 1, [s.1.], 1992, p. 75-116. Disponível em: $<$ https://link.springer.com/article/10.1007/BF02342617> . Acesso em:2017

TEIXEIRA, M. T.; MENUZZI, S. M. Diverse exhaustiveness effects in clefts: a descriptive study. Revista ALFA. UNESP, São José do Rio Preto, n. 59, 2015, p. 59-87.

VELLEMAN, D.; BEAVER, D.; DESTRUEL, E.; BUMFORD, D.; ONEA, E.; COPPOCK, L. It-clefts are IT (inquiry terminating) constructions. Semantics and Linguistic Theory, n. 22, [s.1.], 2012, p. 441-460. Disponível em: $<$ https://journals.linguisticsociety.org/proceedings/index.php/SALT/article/view/2

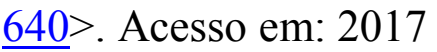

WEDGWOOD, D. Shifting the Focus: From Static Structures to the Dynamics of Interpretation. Oxford: Elsevier, 2005.

WEDGWOOD, D.; PETHÖ, G; CANN, R. Hungarian 'focus position' and English it-clefts: the semantic underspecification of 'focus' readings. South Bridge, Edinburgh: 2006. Ms., Dept. of Linguistics, University of Edinburgh. 
Disponível em: $\quad<$ http://www.lel.ed.ac.uk/ ronnie/JoS-paper forESRC.pdf $>$. Acesso em: 2017

ZUBIZARRETA, M. L. Prosody, focus, and word order. Cambridge (EUA): MIT Press, 1998.

Recebido em: 6 jan. 2018 Aceito em: 7 abr. 2018

Publicado em: 1 out. 2018 